\title{
Rancangan Kontrol dan Monitoring Constant Current Regulator (CCR) pada Precision Approach Path Indicator (PAPI) Menggunakan Android Berbasis Arduino di Bandar Udara Internasional Lombok
}

\author{
Kustori \\ Zuris Nur Faiza Ningrum \\ Program Studi Diploma III Teknik Listrik Bandar Udara \\ Akademi Teknik dan Keselamatan Penerbangan Surabaya \\ Jl.Jemur Andayani 1/73 Wonocolo Surabaya 60236 \\ Telp.(031)841087, Fax.(031)8490005
}

\begin{abstract}
Constant Current Regulator is a power supply used in the world of aviation for the provision of electric power in airport lighting systems. The electrical power supplied to the airport lighting lamp is maintained to provide power with constant current. It is intended that the runway lights, especially PAPI, has lighting in certain light brightness / intensity that we want according to the specified taping.

At this time, CCR in Lombok International Airport has been using SCADA. Unfortunately for controlling and monitoring CCR on a runway lights especially PAPI can only be done in the control room, so engineers had to stand by in the control room.

By given this design, android is expected to replace the SCADA that can be accessed remotely, no matter where technicians are located. Moreover, when the state requires you to change the CCR step, the technician can control CCR through android system in technician's smartphone once monitor the CCR output current without having to stand by in the control room.
\end{abstract}

Keywords: Constant Current Regulator (CCR), Precission Approach Path Indicator (PAPI), Android, smartphone.

\section{Pendahuluan}

Bandar Udara adalah kawasan di daratan dan atau perairan dengan batas-batas tertentu yang digunakan sebagai tempat pesawat udara mendarat dan lepas landas, naik turun penumpang, bongkar muat barang, dan tempat perpindahan intra dan antar moda transportasi, yang dilengkapi dengan fasilitas keselamatan dan keamanan penerbangan, serta fasilitas pokok dan fasilitas penunjang lainnya. Bandar udara mampu melayani rute dalam negeri dan melayani rute penerbangan dari dan keluar negeri, serta sebagai kawasan di daratan dan atau di perairan dengan batas-batas tertentu dalam wilayah Republik Indonesia yang digunakan untuk kegiatan lepas landas dan pendaratan pesawat udara guna keperluan pertahanan negara oleh Tentara Nasional Indonesia.

Pada saat ini Indonesia telah memiliki Bandar Udara yang tersebar di seluruh wilayah Indonesia mulai dari daerah perkotaan hingga daerah pedalaman. Perkembangan penerbangan yang sangat pesat ini, menyebabkan banyaknya bandara-bandara yang semakin besar dan lengkap dalam waktu yang sangat cepat. Mulai dari Bandara internasional hingga Bandara perintis di seluruh Indonesia. Seperti contohnya Bandar Udara Internasional Lombok yang 
merupakan salah satu bandara milik Negara yang dinaungi oleh Pemerintah Provinsi Nusa Tenggara Barat. Bandara ini dioperasikanoleh PT Angkasa Pura I.

Bandar Udara Internasional Lombok dibuka pertama kali pada tanggal 1 oktober 2011 untuk menggantikan fungsi dari Bandara Selaparang Mataram. Terletak persis di jantung pulau Lombok tepatnya di Jalan Tanak Awu, Kabupaten Lombok Tengah, pulau Lombok, Indonesia. Bandara ini terletak sebelah tenggara Kota Mataram ibu kota provinsi Nusa Tenggara Barat dan \pm 8 kilometer selatan dari kota kecil Praya, ibu kota Kabupaten Lombok Tengah. Pada tanggal 20 oktober 2011 Bandar Udara Internasional Lombok diresmikan oleh Presiden RI Susilo Bambang Yudhoyono di atas lahan seluas 550 hektare yang menelan biaya Rp. 625 miliar rupiah.

Perkembangan tersebut dimulai dari tahap pertama pada tahun 2006 sampai dengan tahun 2009 yaitu dengan membangun runway 45m x 2500m, appron $52.074 \mathrm{~m}^{2}$, taxiway 2 exit taxiway, terminal $12.000 \mathrm{~m}^{2}$ (penumpang, vip, kargo), dan parkir $17.500 \mathrm{~m}^{2}$. Pada tahap kedua yaitu pada tahun 2013 sampai dengan 2015 dibangun runway 45m x 2750m, appron $63.294 \mathrm{~m}^{2}$, taxiway 2 exit taxiway, terminal $16.500 \mathrm{~m}^{2}$ (2,4 juta penumpang per tahun), dan parkir 29.100 $\mathrm{m}^{2}$. Hingga tahap ketiga yang masih dalam rencana akan dibangun pada tahun 2028, yaitu dengan membangun runway $45 \mathrm{~m} \times 3500 \mathrm{~m}$, appron $74.514 \mathrm{~m}^{2}$, taxiway (taxiway keluar dari 12, 2 taxiway keluar yang cepat, 1 paralel taxiway), terminal $28.750 \mathrm{~m}^{2}$ (3.25 juta penumpang per tahun), dan parkir $29.100 \mathrm{~m}^{2}$.

Hampir seluruh Bandar Udara berkategori III dan IV masih belum memiliki sebuah peralatan yang dapat memonitoring Constant Current Regulator (CCR) pada lampu Precission Approach Path Indicator (PAPI), yang mana lampu PAPI level pencahayaannya harus tepat. Kondisi ini sangat memberatkan seorang teknik listrik dalam melaksanakan memonitoring level pencahayaan lampu, arus, tegangan, dan daya masih dilakukan dengan jarak dekat. Yaitu mengontrol dan memonitoring secara visual dengan melihat langsung pada layar SCADA di ruang kontrol.

Pada Bandar Udara berkategori I seperti contohnya di Bandar Udara Internasional Lombok telah menggunakan sebuah peralatan pengontrolan dan pemonitoringan CCR yaitu dengan menggunakan sistem SCADA. Alat ini merupakan peralatan terbaru yang mampu mengetahui dan memonitoring CCR yang terdapat di substation dengan jarak yang sangat jauh. Tetapi hingga saat ini Bandar Udara berkategori III dan IV masih belum dapat menfasilitasi peralatan ini dikarenakan harganya yang sangat mahal. Permasalahan lain dari pemonitoringan CCR pada PAPI adalah jarak CCR dengan tempat pemonitoringan yang sangat jauh.

Di Perusahaan Listrik Negara (PLN) sebenarnya telah menggunakan prinsip kerja dari android atau smartphone. Android atau smartphone ini merupakan sebuah metode untuk berkomunikasi atau mengirim sebuah data jarak jauh dengan menggunakan media yang telah ada yaitu web. Landasan inilah yang akan digunakan penulis untuk mengaplikasikan prinsip kerja android atau smartphone sebagai media memonitoring CCR yang berjarak sangat jauh.

Oleh karena itu penulis bermaksud menyelesaikan permasalahan-permasalahan di atas dengan membuat sebuah rancangan yaitu Rancangan Kontrol dan Monitoring Constant Current Regulator (CCR) pada Precision Approach Path Indicator (PAPI) menggunakan Android Berbasis Arduino di Bandar Udara Internasional Lombok. Agar kelancaran dalam pelayanan penerbangan terjaga. Dari permasalahan tersebut kemudian dirumuskan Rumusan masalah sebagai berikut: (1) Bagaimana cara mengontrol dan memonitoring CCR lampu PAPI dengan menggunakan sistem yang lebih canggih? (2) Bagaimana data CCR dapat dikirim dengan jarak jauh tanpa teknisi harus stand by di ruang kontrol? 


\section{Landasan Teori \\ Sistem Kontrol}

Kontrol automatik telah memegang peranan yang sangat penting dalam perkembangan ilmu dan teknologi. Disamping sangat diperlukan dalam peralatan canggih seperti pada pesawat luar angkasa, peluru kendali, sistem pengemudian pesawat terbang; kontrol automatik telah digunakan dalam proses-proses diberbagai pabrik-pabrik dan industri yang sudah maju misalnya dalam mengontrol tekanan, temperatur, kelembaban, viskositas, dan aliran dalam industri proses. Dengan adanya kontrol automatik akan memberikan kemudahan dalam mendapatkan performansi dan sistem dinamik, mempertinggi kualitas dan menurunkan biaya produksi, mempertinggi laju produksi, mengurangi tenaga pekerja yang kurang efisien, dan menggantikan tenaga-tenaga yang tidak bisa dilakukan oleh manusia.

\section{Constant Current Regulator (CCR)}

CCR merupakan suatu catu daya yang digunakan dalam dunia penerbangan untuk pemberian tenaga listrik pada sistem penerangan bandara. Dimana pada tenaga listrik yang diberikan untuk lampu penerangan bandara ini dipertahankan memberikan suplai tenaga dengan arus tetap. Hal ini bertujuan agar lampu memiliki penerangan dengan brightness/intensitas cahaya yang kita inginkan sesuai dengan taping yang ditentukan. Di Bandar Udara ada beberapa macam CCR yang digunakan seperti Constant Current Regulator (CCR) tipe NBF 1200, Thyristor Current Regulator (TCR), dan Micropocessor Current Regulator (MCR).

\section{Precission Approach Path Indicator (PAPI)}

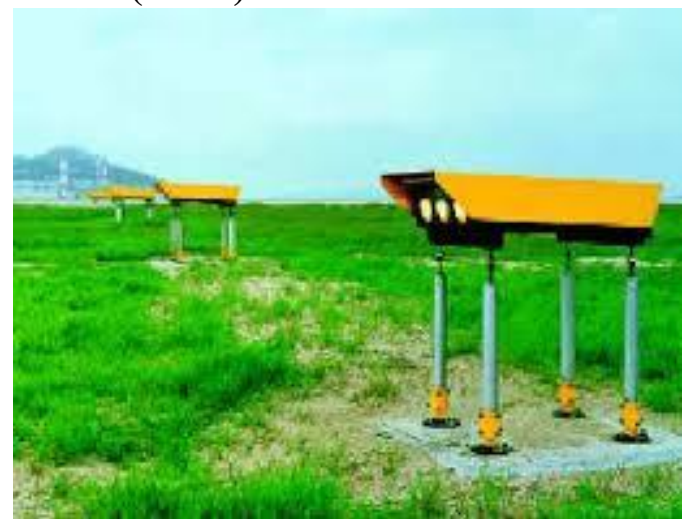

Gambar 1 Lampu PAPI

(Sumber: http://www.elektro- uncen.tripod.com)

Precision Approach Path Indicator (PAPI) merupakan alat bantu pendaratan pesawat udara yang membutuhkan kepresisian sudut slope yang sangat teliti (sekitar $3^{\circ}$ ), dan melalui pancaran cahaya yang dihasilkan oleh PAPI untuk menuntun pesawat udara melakukan pendaratan yang nyaman tepat pada Touch down zone.

VASI dan PAPI digunakan untuk memberikan panduan melalui pancaran cahaya kepada pilot pesawat apakah sudut pendekatan pada saat mendarat sudah tepat atau tidak. Sesuai dengan rekomendasi ICAO, sejak januari 1995 VASI digantikan oleh PAPI kecuali T-VASIS.

PAPI terdiri atas 4 unit terpasang pada sisi kiri landasan (dilihat dari arah pesawat) atau kanan kiri landasan. Setiap unit PAPI memancarkan sinar putih merah dengan batas horizontal, sudut-sudut tiap unit PAPI di atur sedemikian rupa sehingga menghasilkan kombinasi warna yang dipancarkan pada setiap posisi pesawat. 
1. Apabila sudut pendaratan di set $3^{\circ}$ atau "on slope" terlihat warna yang dipancarkan 2 unit akan berwarna merah dan 2 unit berwarna putih (warna putih pada sisi luar dari landasan)

2. Apabila posisi pesawat terlalu tinggi, terlihat warna putih makin bertambah dan warna merah makin berkurang.

3. Apabila posisi pesawat terlalu rendah, terlihat warna merah makin bertambah dan warna putih makin berkurang.

Karena itu pemasangan PAPI diharapkan akan memberikan:

1. Jaminan seminim mungkin sentuhan mulus roda terhadap ambang landasan.

2. Memberikan batas jelas dari semua rintangan ketika sampai pada pendaratan terakhir.

Jalur kecil (approach path) pendaratan, membimbing pesawat pada titik touch down secara tepat tanpa melihat keadaan atau karakteristik landasan.

\section{Sistem Android}

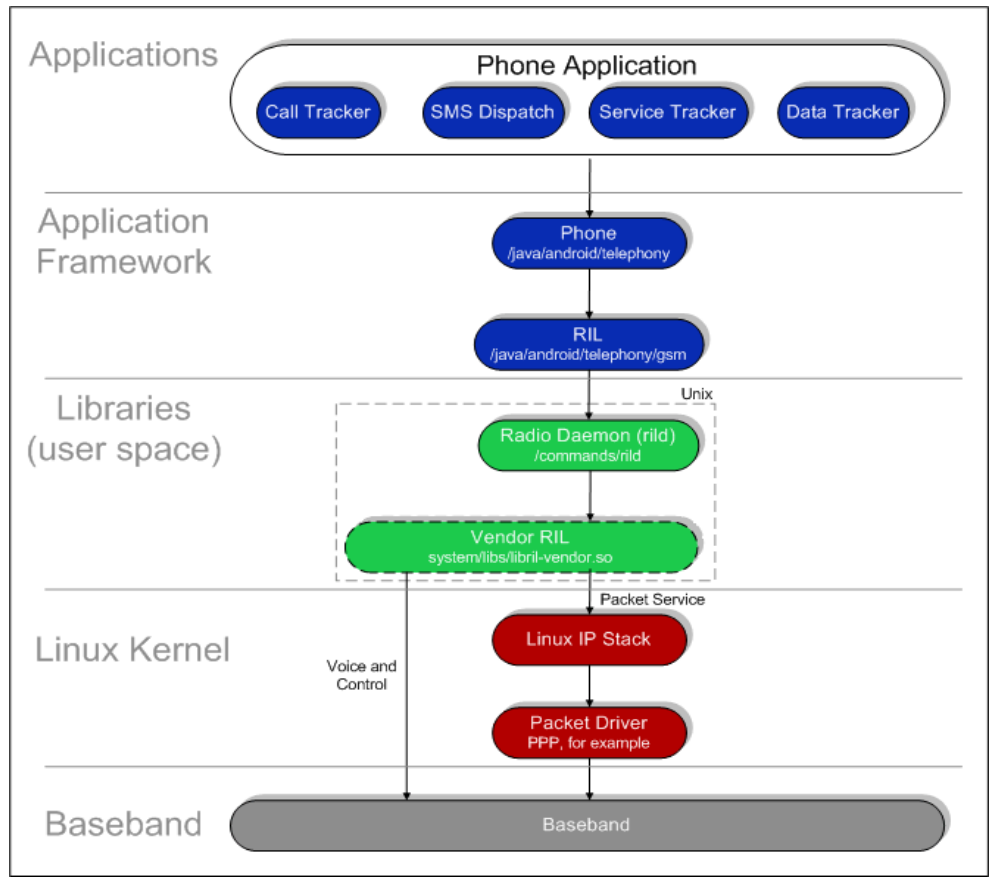

Gambar 2 Android

(Sumber: www.netmite.com/android)

Android adalah sebuah kumpulan perangkat lunak untuk perangkat mobile yang mencakup sistem operasi, middleware dan aplikasi utama mobile. Android memiliki empat karakteristik sebagai berikut:

1. Terbuka Android dibangun untuk benar-benar terbuka sehingga sebuah aplikasi dapat memanggil salah satu fungsi inti ponsel seperti membuat panggilan, mengirim pesan teks, menggunakan kamera, dan lain-lain. Android menggunakan sebuah mesin virtual yang dirancang khusus untuk mengoptimalkan sumber daya memori dan perangkat keras yang terdapat di dalam perangkat. Android merupakan open source, dapat secara bebas diperluas untuk memasukkan teknologi baru yang lebih maju pada saat teknologi tersebut muncul. Platform ini akan terus berkembang untuk membangun aplikasi mobile yang inovatif.

2. Semua aplikasi dibuat sama Android tidak memberikan perbedaan terhadap aplikasi utama dari telepon dan aplikasi pihak ketiga (third-party application). Semua aplikasi dapat 
dibangun untuk memiliki akses yang sama terhadap kemampuan sebuah telepon dalam menyediakan layanan dan aplikasi yang luas terhadap para pengguna.

3. Memecahkan hambatan pada aplikasi Android memecah hambatan untuk membangun aplikasi yang baru dan inovatif. Misalnya, pengembang dapat menggabungkan informasi yang diperoleh dari web dengan data pada ponsel seseorang seperti kontak pengguna, kalender, atau lokasi geografis.

Pengembangan aplikasi yang cepat dan mudah Android menyediakan akses yang sangat luas kepada pengguna untuk menggunakan library yang diperlukan dan tools yang dapat digunakan untuk membangun aplikasi yang semakin baik. Android memiliki sekumpulan tools yang dapat digunakan sehingga membantu para pengembang dalam meningkatkan produktivitas pada saat membangun aplikasi yang dibuat. Google Inc. sepenuhnya membangun Android dan menjadikannya bersifat terbuka (open source) sehingga para pengembang dapat menggunakan Android tanpa mengeluarkan biaya untuk lisensi dari Google dan dapat membangun Android tanpa adanya batasan-batasan. Android Software Development Kit (SDK) menyediakan alat dan Application Programming Interface (API) yang diperlukan untuk mulai mengembangkan aplikasi pada platform Android menggunakan bahasa pemrograman Java.

\section{Mikrokontroller Arduino}

Mikrokontroler Arduino adalah pengendali mikro single-board yang bersifat open-source, diturunkan dari Wiring plat form, dirancang untuk memudahkan penggunaan elektronik dalam berbagai bidang. Perangkat kerasnya memiliki prosesor Atmel AVR dan perangkat lunaknya memiliki bahasa pemrograman sendiri. Saat ini Arduino sangat populer di seluruh dunia. Banyak pemula yang belajar mengenal robotika dan elektronika lewat Arduino karena mudah dipelajari. Bahasa yang dipakai dalam Arduino bukan assembler yang relatif sulit, tetapi bahasa yang disederhanakan dengan bantuan pustaka-pustaka (libraries) Arduino. Arduino juga menyederhanakan proses bekerja dengan mikrokontroler, sekaligus menawarkan berbagai macam kelebihan.

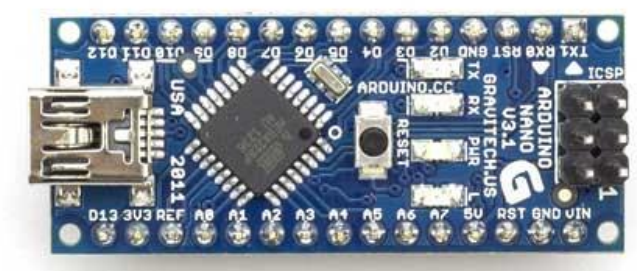

Gambar 3 Rangkaian Mikrokontroler Arduiono

(Sumber: http $/ /$ www.arduino.cc)

\section{HASIL DAN ANALISIS \\ Pengujian Power Supply}

Pembuatan rangkaian dimulai dari power supply dengan mengukur input dari power supply untuk tegangan positif dan tegangan negatif. Power supply pada rancangan ini menggunakan dua buah adaptor dengan output antara lain 24 VDC dengan arus sebesar 2A dan 12 VDC dengan arus sebesar 3A. Tegangan input adaptor ini adalah 100 - 240 VAC. Didalam adaptor tersebut ada sebuah transformator yang berguna untuk menurunkan tegangan-tegangan AC, kemudian 
disearahkan terlebih dahulu menggunakan jembatan diode. Setelah melewati proses penyearahan dilakukan proses filter untuk meminimalisir riple. Sehingga menghasilkan output tegangan DC yang stabil. Power supply 24V ini digunakan untuk masukan solenoid. Sedangkan power supply $12 \mathrm{~V}$ digunakan untuk masukan Mikrokontroller serta Sensor Arus dan diberi rangkaian regulator sehingga tegangan output menjadi $5 \mathrm{~V}$. Setelah alat sudah dirancang sedemikian rupa maka dilakukan analis is sebagai berikut:

Tabel 1 Pengujian Power Supply

\begin{tabular}{|c|c|c|c|}
\hline No & Tegangan Input (v) & $\begin{array}{c}\text { Tegangan Output } \\
24 \mathrm{~V}\end{array}$ & $\begin{array}{c}\text { Tegangan Output } \\
12 \mathrm{~V}\end{array}$ \\
\hline 1 & $220 \mathrm{Vac}$ & $24.11 \mathrm{Vdc}$ & $12.1 \mathrm{Vdc}$ \\
\hline 2 & $223 \mathrm{Vac}$ & $24.13 \mathrm{Vdc}$ & $12.12 \mathrm{Vdc}$ \\
\hline 3 & $224 \mathrm{Vac}$ & $24.13 \mathrm{Vdc}$ & $12.14 \mathrm{Vdc}$ \\
\hline 4 & $227 \mathrm{Vac}$ & $24.15 \mathrm{Vdc}$ & $12.16 \mathrm{Vdc}$ \\
\hline 5 & $230 \mathrm{Vac}$ & $24.17 \mathrm{Vdc}$ & $12.16 \mathrm{Vdc}$ \\
\hline 6 & $233 \mathrm{Vac}$ & $24.17 \mathrm{Vdc}$ & $12.17 \mathrm{Vdc}$ \\
\hline
\end{tabular}

(Sumber :Hasil Olahan Penulis)

Tegangan input dari power supply diatas tidak 220 Vac melainkan terdapat losses rata rata tegangan sekitar 1 volt yang dapat disebabkan beberapa hal seperti tahanan kabel dan yang lainnya namun masih tetap pada batas toleransi karena tegangan ini berasal dari sumber PLN. Sebaliknya untuk tegangan output terdapat selisih antara $0.4 \mathrm{Vdc}$ yang disebabkan karena Losses dari rangkaian power supply itu sendiri.

\section{Pengujian PORT Mikrokontroler}

Pengujian PORT mikrokontroler dilakukan pada setiap pin, dimana pada setiap pin di setting aktifkan high dan low secara bergantian dengan demikian maka dapat diketahui data tegangan output dari mikrokontroler. Berikut ini adalah gambar pengujian PORT mikrokontroler pada setiap pin. 


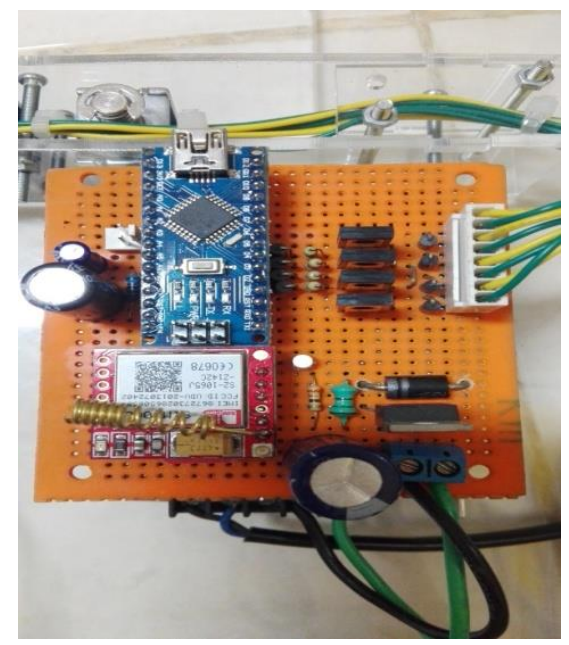

Gambar 4 PengujianTegangan Masing-Masing Port

(Sumber: Hasil Karya Penulis)

Tabel 2 Pengujian Port Mikrokontroler

\begin{tabular}{|c|c|c|c|c|c|c|}
\hline \multirow{3}{*}{$\boldsymbol{P I N}$} & \multicolumn{7}{|c|}{ PORT } \\
\cline { 2 - 7 } & B & & C & & D & \\
\cline { 2 - 7 } & High (Volt) & Low (Volt) & High (Volt) & Low (Volt) & High (Volt) & Low (Volt) \\
\hline 0 & 4,69 & 0 & 4,74 & 0 & 4,68 & 0 \\
\hline 1 & 4,69 & 0 & 4,74 & 0 & 4,68 & 0 \\
\hline 3 & 4,69 & 0 & 4,74 & 0 & 4,68 & 0 \\
\hline 4 & 4,69 & 0 & 4,74 & 0 & 4,68 & 0 \\
\hline 5 & 4,70 & 0 & 4,74 & 0 & 4,68 & 0 \\
\hline 6 & 4,70 & 0 & 4,74 & 0 & 4,68 & 0 \\
\hline 7 & 4,70 & 0 & 4,74 & 0 & 4,68 & 0 \\
\hline
\end{tabular}

(Sumber: Hasil Pengujian Penulis)

Dari hasil pengujian di tiap port sistem minimum, didapatkan hasil bahwa Port B, Port C dan Port D terdapat tegangan apabila diberikan active high dan tidak terdapat tegangan apabila diberikan active low. Setiap port pada sistem minimum berbeda karena sistem minimum mempunyai fungsi masing - masing. Di setiap pin pada semua port tidak terdapat masalah atau cacat pada kaki - kaki pin.

\section{Pengujian Driver Solenoid}

Pengujian driver solenoid dilakukan dengan cara mengaktifkan seluruh port mikrokontroler yang nantinya sebagai pemicu aktifnya solenoid, kemudian pada port output dari driver solenoid disambungkan dengan voltmeter, sehingga didapatkan data tegangan output driver solenoid tersebut. 


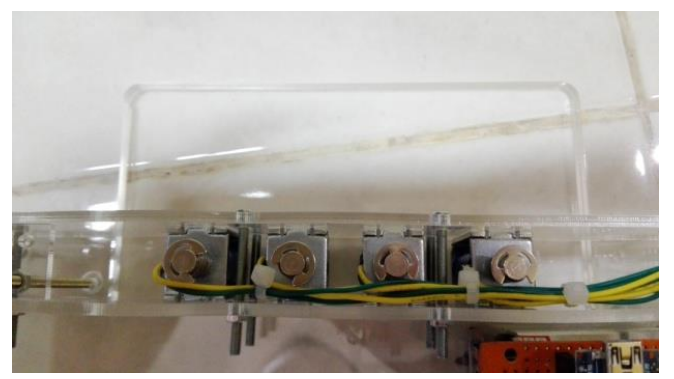

Gambar 5 Rangkaian Driver Solenoid (Sumber: Hasil Karya Penulis)

Tabel 3 Pengujian Solenoid

\begin{tabular}{|c|c|c|c|c|}
\hline Voltage & Solenoid 1 & Solenoid 2 & Solenoid 3 & Solenoid 4 \\
\hline High $(24 \mathrm{~V})$ & 22.79 & 22.83 & 22.78 & 22.81 \\
\hline Low $(12 \mathrm{~V})$ & 10.63 & 11.12 & 11.54 & 11.37 \\
\hline Low $(0)$ & 0 & 0 & 0 & 0 \\
\hline
\end{tabular}

(Sumber: Hasil Pengujian Penulis)

Dari hasil pengujian Solenoid di atas, power supply dengan tegangan $12 \mathrm{Vdc}$ tidak dapat memaksimalkan penekanan solenoid terhadap tombol CCR. Oleh karena itu solenoid memakai power supply dengan tegangan $24 \mathrm{Vdc}$.

\section{Pengujian Transformator Arus}

Dengan menggunakan beban lampu bohlam yang bervariasi antara 100 Watt sampai dengan 500 Watt. Pengujian Transformator arus dilakukan dengan cara membandingkan antara hasil pembacaan sensor setelah di olah dengan mikrokontroler menggunakan Amperemeter digital.

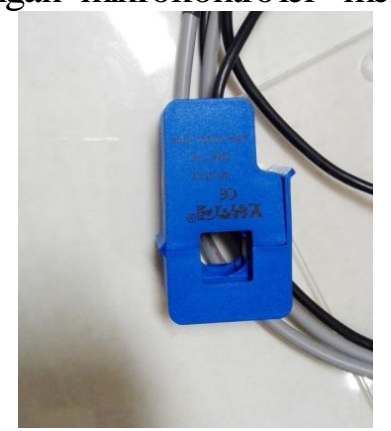

Gambar 6 Driver Transformator Arus

(Sumber : Hasil Karya Penulis)

Tabel 4 Pengujian Transformator Arus

\begin{tabular}{|c|c|c|}
\hline Beban & $\begin{array}{c}\text { Mikrokontroler } \\
\text { (A) }\end{array}$ & $\begin{array}{c}\text { Amperemeter } \\
\text { (A) }\end{array}$ \\
\hline $100 \mathrm{~W}$ & 0.46 & 0.45 \\
\hline $200 \mathrm{~W}$ & 0.90 & 0.90 \\
\hline $300 \mathrm{~W}$ & 1.36 & 1.35 \\
\hline $400 \mathrm{~W}$ & 1.81 & 1.80 \\
\hline $500 \mathrm{~W}$ & 2.25 & 2.25 \\
\hline
\end{tabular}

(Sumber : Hasil Karya Penulis) 
Dari tabel pengujian transformator arus diatas dengan toleransi pembacaan $\pm 0.01 \mathrm{~A}$ dianggap sama karena adanya error dalam pembacaan.

\section{Pengujian aplikasi Android}

Pengujian aplikasi Android ini pada smartphone dilakukan dengan menjalankan aplikasi. Sebelum masuk ke apilkasi pengguna smartphone Android harus memiliki softwere CCR.apk untuk menjalankan aplikasi android pada smartphone. Setelah memiliki aplikasi tersebut pengguna atau teknisi akan mendapatkan tampilan seperti gambar dibawah ini:

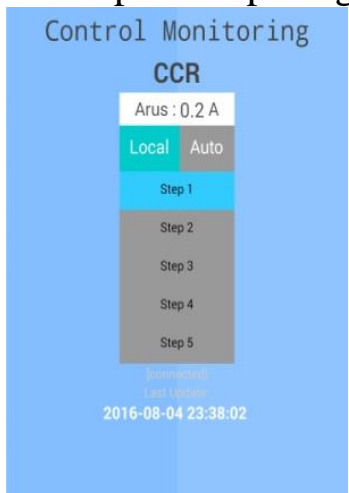

Gambar 7 Display Android

(Sumber: Hasil Karya Penulis)

\section{Pengujian Sistem}

Pengujian ini dilakukan setelah alat dipasang ke CCR, dan dilakukan uji coba untuk menaikkan step brightness dari step 1 - 5 agar dapat dihitung nilai persen errornya saat pengujian alat dengan cara menyalakan rangkaian alat, menyambungkan android dengan modem rangkaian, dan mengganti level brightness satu per satu.

Tabel 5 Pengujian Step Brightness

\begin{tabular}{|c|c|c|c|c|c|c|c|c|c|}
\hline No. & Step 1 & Step 2 & Step 3 & Step 4 & Step 5 & Step 4 & Step 3 & Step 2 & Step 1 \\
\hline 1 & $\checkmark$ & $\checkmark$ & $\checkmark$ & $\checkmark$ & $\checkmark$ & $\checkmark$ & $\checkmark$ & $\checkmark$ & $\checkmark$ \\
\hline 2 & $\checkmark$ & $\checkmark$ & $\checkmark$ & $\checkmark$ & $\checkmark$ & $\checkmark$ & $\checkmark$ & $\checkmark$ & $\checkmark$ \\
\hline 3 & $\checkmark$ & $\checkmark$ & $\checkmark$ & $\checkmark$ & $\checkmark$ & $\checkmark$ & $\checkmark$ & $\checkmark$ & $\checkmark$ \\
\hline 4 & $X$ & $\checkmark$ & $\checkmark$ & $\checkmark$ & $\checkmark$ & $\checkmark$ & $\checkmark$ & $\checkmark$ & $\checkmark$ \\
\hline 5 & $\checkmark$ & $\checkmark$ & $\checkmark$ & $\checkmark$ & $\checkmark$ & $\checkmark$ & $\checkmark$ & $\checkmark$ & $\checkmark$ \\
\hline 6 & $\checkmark$ & $\checkmark$ & $\checkmark$ & $\checkmark$ & $\checkmark$ & $\checkmark$ & $\checkmark$ & $\checkmark$ & $\checkmark$ \\
\hline 7 & $\checkmark$ & $\checkmark$ & $\checkmark$ & $\checkmark$ & $\checkmark$ & $\checkmark$ & $\checkmark$ & $\checkmark$ & $\checkmark$ \\
\hline 8 & $\checkmark$ & $\checkmark$ & $\checkmark$ & $\checkmark$ & $\checkmark$ & $\checkmark$ & $\checkmark$ & $\checkmark$ & $\checkmark$ \\
\hline 9 & $\checkmark$ & $\checkmark$ & $\checkmark$ & $\checkmark$ & $X$ & $\checkmark$ & $\checkmark$ & $\checkmark$ & $\checkmark$ \\
\hline 10 & $\checkmark$ & $\checkmark$ & $\checkmark$ & $\checkmark$ & $\checkmark$ & $\checkmark$ & $\checkmark$ & $\checkmark$ & $\checkmark$ \\
\hline 11 & $\checkmark$ & $\checkmark$ & $\checkmark$ & $\checkmark$ & $\checkmark$ & $\checkmark$ & $\checkmark$ & $\checkmark$ & $\checkmark$ \\
\hline 12 & $\checkmark$ & $\checkmark$ & $\checkmark$ & $\checkmark$ & $\checkmark$ & $\checkmark$ & $\checkmark$ & $\checkmark$ & $\checkmark$ \\
\hline 13 & $\checkmark$ & $\checkmark$ & $\checkmark$ & $\checkmark$ & $\checkmark$ & $\checkmark$ & $\checkmark$ & $\checkmark$ & $\checkmark$ \\
\hline 14 & $\checkmark$ & $\checkmark$ & $\checkmark$ & $\checkmark$ & $\checkmark$ & $\checkmark$ & $\checkmark$ & $\checkmark$ & $\checkmark$ \\
\hline 15 & $\checkmark$ & $\checkmark$ & $\checkmark$ & $\checkmark$ & $\checkmark$ & $\checkmark$ & $\checkmark$ & $\checkmark$ & $\checkmark$ \\
\hline 16 & $\checkmark$ & $\checkmark$ & $\checkmark$ & $\checkmark$ & $\checkmark$ & $\checkmark$ & $\checkmark$ & $\checkmark$ & $\checkmark$ \\
\hline 17 & $\checkmark$ & $\checkmark$ & $\checkmark$ & $\checkmark$ & $\checkmark$ & $\checkmark$ & $\checkmark$ & $\checkmark$ & $\checkmark$ \\
\hline 18 & $\checkmark$ & $\checkmark$ & $\checkmark$ & $X$ & $\checkmark$ & $\checkmark$ & $\checkmark$ & $\checkmark$ & $\checkmark$ \\
\hline
\end{tabular}




\begin{tabular}{|c|c|c|c|c|c|c|c|c|c|}
\hline 19 & $\checkmark$ & $\checkmark$ & $\checkmark$ & $\checkmark$ & $\checkmark$ & $\checkmark$ & $\checkmark$ & $\checkmark$ & $\checkmark$ \\
\hline 20 & $\checkmark$ & $\checkmark$ & $\checkmark$ & $\checkmark$ & $\checkmark$ & $\checkmark$ & $\checkmark$ & $\checkmark$ & $\checkmark$ \\
\hline 21 & $\checkmark$ & $\checkmark$ & $\checkmark$ & $\checkmark$ & $\checkmark$ & $\checkmark$ & $\checkmark$ & $\checkmark$ & $\checkmark$ \\
\hline 22 & $\checkmark$ & $\checkmark$ & $\checkmark$ & $\checkmark$ & $\checkmark$ & $\checkmark$ & $\checkmark$ & $\checkmark$ & $\checkmark$ \\
\hline 23 & $\checkmark$ & $\checkmark$ & $\checkmark$ & $\checkmark$ & $\checkmark$ & $\checkmark$ & $\checkmark$ & $\checkmark$ & $\checkmark$ \\
\hline 24 & $\checkmark$ & $\checkmark$ & $\checkmark$ & $\checkmark$ & $\checkmark$ & $\checkmark$ & $\checkmark$ & $\checkmark$ & $\checkmark$ \\
\hline 25 & $\checkmark$ & $\checkmark$ & $\checkmark$ & $\checkmark$ & $\checkmark$ & $\checkmark$ & $\checkmark$ & $\checkmark$ & $\checkmark$ \\
\hline 26 & $\checkmark$ & $\checkmark$ & $\checkmark$ & $\checkmark$ & $\checkmark$ & $\checkmark$ & $\checkmark$ & $\checkmark$ & $\checkmark$ \\
\hline 27 & $\checkmark$ & $\checkmark$ & $\checkmark$ & $\checkmark$ & $\checkmark$ & $\checkmark$ & $\checkmark$ & $\checkmark$ & $\checkmark$ \\
\hline 28 & $\checkmark$ & $\checkmark$ & $\checkmark$ & $\checkmark$ & $\checkmark$ & $\checkmark$ & $\checkmark$ & $\checkmark$ & $\checkmark$ \\
\hline 29 & $\checkmark$ & $\checkmark$ & $\checkmark$ & $\checkmark$ & $\checkmark$ & $\checkmark$ & $\checkmark$ & $\checkmark$ & $\checkmark$ \\
\hline 30 & $\checkmark$ & $\checkmark$ & $\checkmark$ & $\checkmark$ & $\checkmark$ & $\checkmark$ & $\checkmark$ & $\checkmark$ & $\checkmark$ \\
\hline
\end{tabular}

(Sumber: Hasil Pengujian Penulis)

Dari hasil pengujian keseluruhan, 267 dari 270 kali merubah step brightness berhasil, dan 3 sisanya terdapat error dikarenakan gangguan pada jaringan internet atau modem.

Jadi persentase error pada rangkaian alat ini adalah:

$$
\begin{aligned}
& \frac{267}{270} \times 100 \%=98.8 \% \text { Persentase berhasil. } \\
& 100 \%-98.8 \%=1.2 \% \text { Persentase } \text { error }
\end{aligned}
$$

\section{Kesimpulan}

Setelah merancang penggunaan android untuk mengontrol dan memonitoring CCR pada lampu PAPI di harapkan dapat di aplikasikan di Bandar Udara sebagaimana yang telah dijelaskan pada bab - bab sebelumnya maka dapat diambil kesimpulan yaitu :

1. Solenoid digunakan untuk rangkaian kontrol CCR dengan tegangan yang besar, namun rangkaian mikrokontroller tidak bisa menerima tegangan yang besar, sehingga digunakan power suppply yang berbeda, $24 \mathrm{Vdc}$ untuk solenoid, dan $12 \mathrm{Vdc}$ untuk rangkaian mikrokontroller.

2. Pemonitoringan CCR pada lampu PAPI dapat dilakukan dengan menggunakan sensor arus sebagai penentu adanya arus pada lampu atau menghitung besaran arus.

3. Android dapat digunakan sebagai media mengirim data, suara, dan internet dengan menggunakan media penyaluran melalui kabel modem.

4. Sistem database dibutuhkan untuk penyimpanan data login dan menyimpan data waktu dalam mencatat kondisi lampu.

5. Pemonitoringan dapat dilakukan dengan menggunakan aplikasi android yang di tampilkan pada smartphone.

\section{Saran}

1. Perlu pemonitoringan terhadap tegangan output $\mathrm{CCR}$, dan adanya open circuit atau ketidak normalan pada CCR.

2. Tampilan android yang lebih menarik dan lebih banyak pilihan atau menu.

3. Rangkaian mikrokontroller lebih baik jika langsung dihubungkan dari sistem SCADA.

4. Rancangan perlu disempurnakan dengan dikembangan untuk dapat digunakan sebagai monitoring CCR pada lampu yang berjumlah banyak seperti runway edge light atau pun approach light. 